\title{
Study on Wind Flow around Highway Embankments
}

\author{
Sun-Young Paek ${ }^{1}$, Byung-Hee Nam ${ }^{1}$, Young-Moon Kim², Ki-Pyo You ${ }^{2}$ and Jang-Youl You ${ }^{3}$ \\ ${ }^{1}$ Department of Architecture Engineering, Chonbuk National University, Jeonju, Korea \\ ${ }^{2}$ Department of Architecture Engineering, Chonbuk National University, Jeonju, Korea, Long-Span steel Frame system Research Center \\ ${ }^{3}$ Department of Architecture Engineering Songwon University, Gwangju, Korea
}

\begin{abstract}
The embankments established in conjunction with highway construction significantly influence ambient wind velocity in surrounding agricultural lands. Wind flow at levels lower than the highway embankment is blocked by the embankment so that the wind blows less here than in the surrounding regions thereby greatly affecting the agricultural crops. Various types of damage are incurred due to the road embankments. However, as yet, no study has been conducted on the micro-meteorological changes occurring around embankments. In this paper, a wind tunnel test was conducted to evaluate wind flow before and after construction of a highway embankment. The study showed that the wind speed was reduced by 40 to $60 \%$ after construction of the embankment as compared to the reference wind speed.
\end{abstract}

\section{Introduction}

The embankments required by road construction can affect air flows, thereby changing surrounding temperatures and incurring degradation to crops, such as fruit trees withering, crops being reduced, and flowering delayed. To prevent cold-weather damage resulting from the slowing down of wind flow around embankments, wind passages have been installed around embankments but no significant effects have been achieved. The coldweather damage to fruit trees near to highway embankments is normally experienced in spring when the wind is blowing weakly. Blocked wind flows constitute a major cause of cold-weather damage to crops. The changes to wind flows can create various phenomena, depending on the geographical features, such as strong gusts of wind or reductions in wind speed due to the blocking effect. A large number of studies have been conducted on increased wind speed in mountainous terrains, valleys, and slopes. Jackson and Hunt[1] studied the effect of wind speed increases in low mountainous terrain, where flow separation phenomena did not occur. Bowen[2] studied the mean wind speed in simple twodimensional (2D) mountainous terrain. Taylor and Lee[3] proposed an algorithm that predicted increases in wind speed at the top of simple mountainous terrains. Chock and Cochran[4] conducted a wind tunnel test to study the phenomenon of increasing wind speed on an island consisting of a complex terrain. They proposed an empirical model involving peak and mean wind speed increases that can be applied to real structure designs. Most of the studies were conducted in the upper parts of mountainous terrains where wind speed increases are common. However, few studies have been conducted on wind flow characteristics around the roads constructed through mountainous areas[5][6] .

Fruit trees planted in the bare ground, and grown on the lower reaches of sloping terrain, are particularly sensitive being affected by both temperature and wind speed. Thus, it is necessary to evaluate the effect on temperature and wind speed if road embankments are built in sloping areas. This study aimed to determine the changes in wind speed resulting from the construction of various types of road embankment. The changes in wind speed were determined by use of wind tunnel tests, using a scale reduction model and particle image velocimetry (PIV). The wind tunnel tests were conducted to determine the wind speed before and after the construction of an embankment in order to explain wind flow changes around highway embankment construction.

\section{2 location and study methodology}

An experimental area was selected in agricultural lands where a ground embankment was to be built for highway construction. Prior to the building of the embankment, wind blowing down from the mountain would follow a natural direction of flow. However, after the construction of the embankment this wind flow was significantly affected. A scale reduction ground model was constructed and a wind tunnel test was conducted to evaluate wind flow both before and after construction of the highway embankment. 


\section{Wind tunnel test}

\subsection{Test model}

A wind speed measurement test was conducted with a $1 / 150$ scale reduction model to investigate wind flow around the highway embankment slopes. The wind tunnel test model was constructed so as to include an area with a radius of $1 \mathrm{~km}$ around the embankment. The wind tunnel ground model was made from styrofoam. The dimensions of the wind tunnel were $12 \mathrm{~m}$ in width, $2.5 \mathrm{~m}$ in height, and $40 \mathrm{~m}$ in length. Figure 1 shows the ground model installed inside the wind tunnel. The test aimed to determine changes in wind speed relative to height differences in the surrounding area both before and after the construction of a highway embankment and when the wind was blowing at a constant speed. An omnidirectional wind speed sensor was installed to measure wind speed around the embankment slope and the wind speed was measured using a multi-point anemometer (System 6242 Model 1560). Nineteen locations were selected in order to determine changes in wind speed around the embankment slope. The height difference between the ground and the embankment was larger on the south side of the embankment than on the north side. Because of this, anemometers were only installed on the south side. A wind speed test was conducted at five locations immediately below the embankment slope and 14 other locations surrounding the embankment.

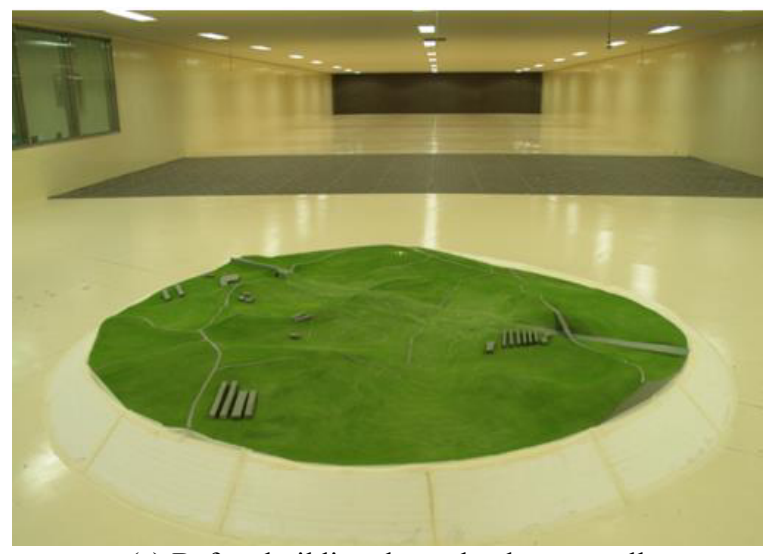

(a) Before building the embankment wall

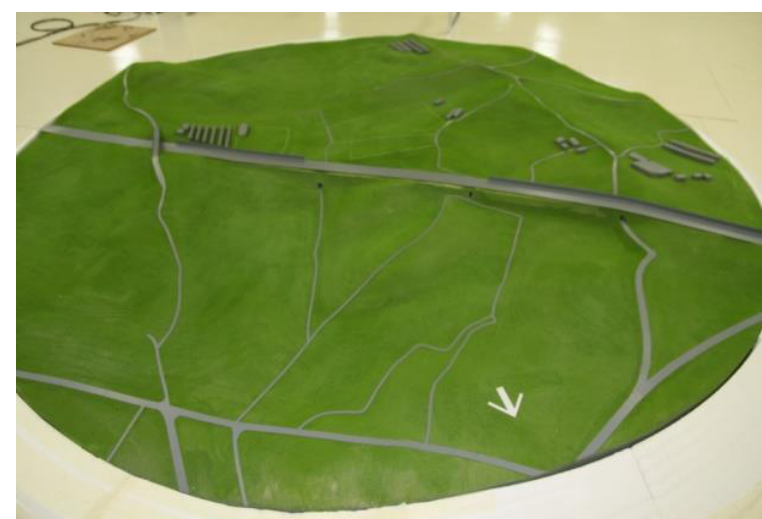

(b) After building the embankment wall

Figure 1. Ground model installed inside the wind tunnel

\subsection{Result of wind speed measurement}

The wind speed used for the wind speed measurement was $3 \mathrm{~m} / \mathrm{s}, 5 \mathrm{~m} / \mathrm{s}$, and $7 \mathrm{~m} / \mathrm{s}$. This test aimed to detect changes in wind speed around the embankment slopes before and after the building of the embankment. Figure 2 shows the wind speed measurement locations and their vertical distances from the embankment top. The surrounding terrain below the embankment had a mean height difference of $8.5 \mathrm{~m}$, with the left side showing the highest difference of $11 \mathrm{~m}$, and the right side showing a $5.9 \mathrm{~m}$ height difference.

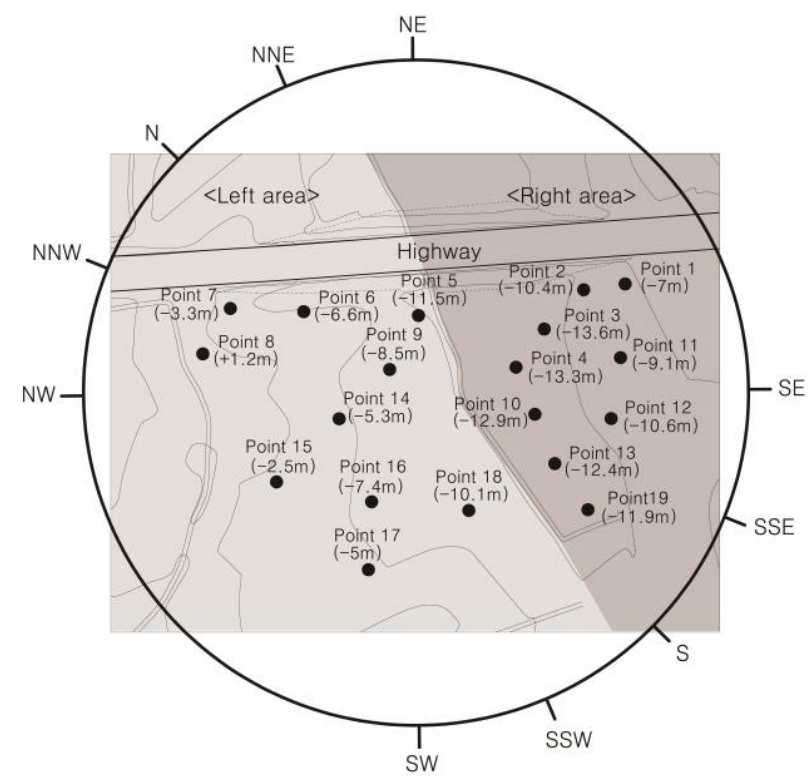

Figure 2. Measurement locations

The test results were analyzed using the concept of wind speed ratio as shown in Equation (1). Three different wind speeds $\left(U_{R}\right)$ were set as reference values $(3 \mathrm{~m} / \mathrm{s}, 5$ $\mathrm{m} / \mathrm{s}, 7 \mathrm{~m} / \mathrm{s}$ ) in the test on the basis of embankment wall height. $\left(U_{h}\right)_{i}$ refers to the wind speed measured at each of 19 locations.

$$
R_{i}=\frac{\left(U_{h}\right)_{i}}{U_{R}}
$$

where $\left(U_{h}\right)_{j}$ is wind speed $(\mathrm{m} / \mathrm{s})$ at $i$ location and $U_{R}$ is the reference wind speed $(\mathrm{m} / \mathrm{s})$.

After the embankment wall was built, many locations experienced a reduced wind speed ratio. Figure 3 shows changes to the wind speed ratio before and after building the embankment wall at measurement locations 4 and 11 , which are located in the same line as measurement location 15. In the legend for Figure 3, "before" means before building the embankment and "after" means after building the embankment. As shown in the figure, the wind speed ratio was reduced after building the embankment. For the center area (measurement locations $4,5,9$, and 10) of the embankment wall, the wind ratio was reduced by $40 \%$ to $60 \%$ which was more than in the other measurement locations. These results revealed that the wind flow was affected by the building of the embankment wall. 


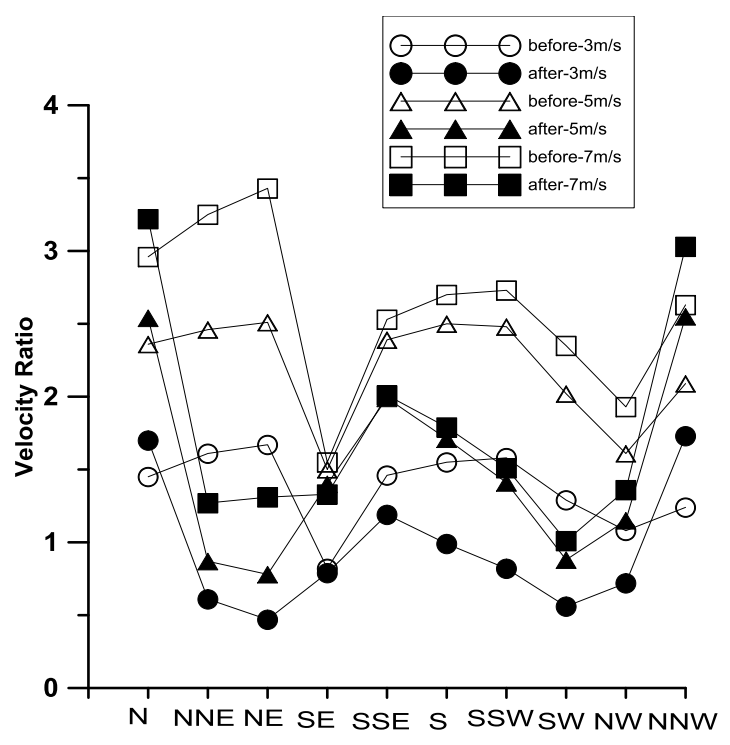

(a) Point 5

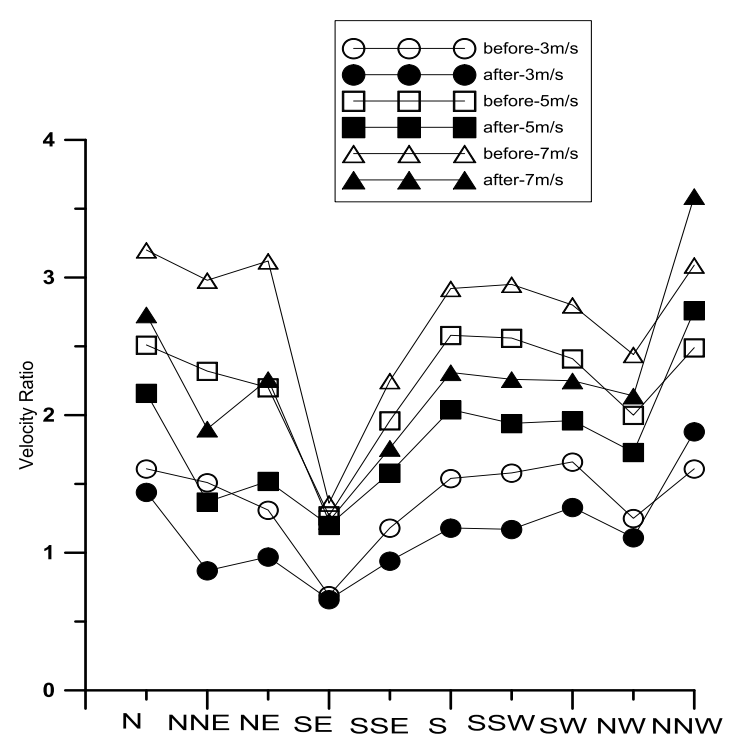

(b) Point 11

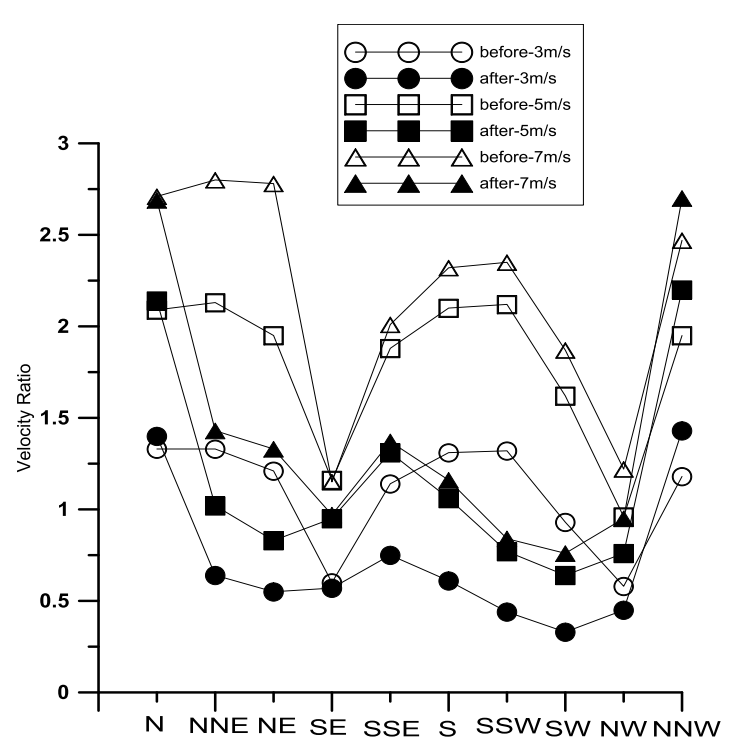

(c) Point 4

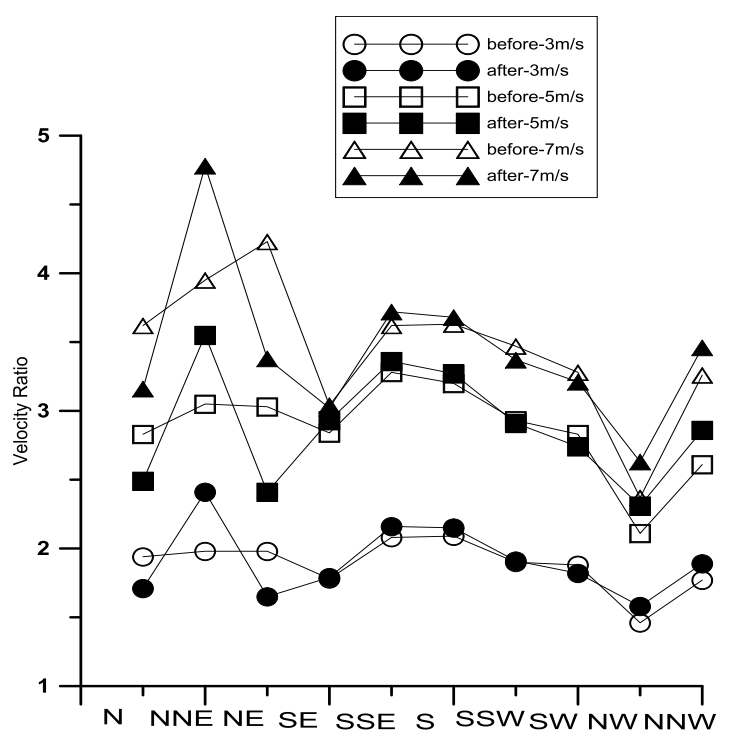

(d) Point 15

Figure 3. Changes in wind speed ratio before and after building the embankment at measurement locations according to changes in wind direction angle.

\section{Experiment of particle image velocimetry (PIV)}

In order to identify wind flow difference shown as relative wind speed vector magnitude before and after construction of the embankment, we used a PIV to interpret velocity distribution and wind profiles of the velocity field. When an embankment tunnel around the fruit farm was established at the center, we horizontally measured two sections (A and $\mathrm{B}$ ) on the right and three sections $(\mathrm{C}, \mathrm{D}$, and $\mathrm{E})$ on the left. Figure 4 shows the measurement locations.

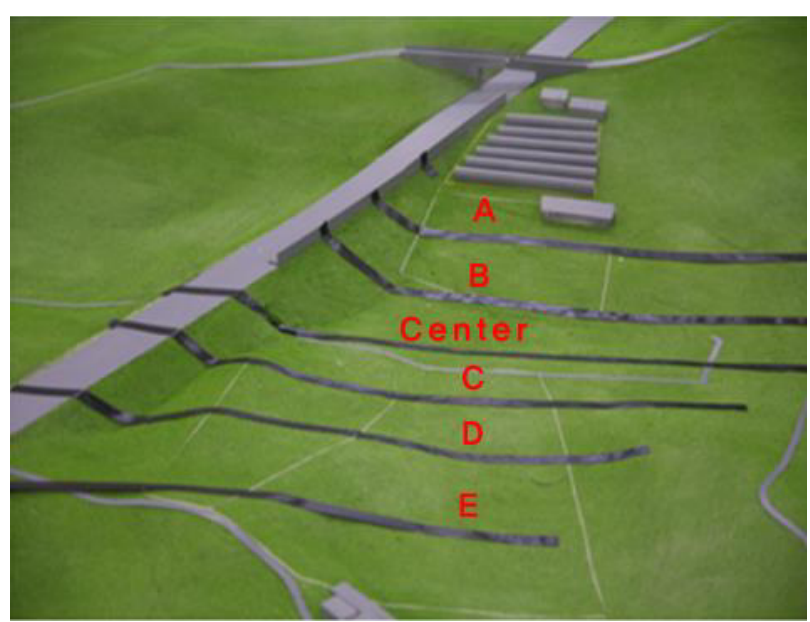

Figure 4. PIV locations for measurement

\subsection{Analysis of measurement results}

The PIV serves as a method for measuring flow velocity by tracking particles scattered with a laser light sheet and obtaining a velocity field on the sheet. We obtained images of 100 captures using cameras located in the five sections under the lower wind velocity of $1 \mathrm{~m} / \mathrm{s}$ or less in the wind tunnels, images that were used to obtain the average velocity field. Figures 5 and 6 show the velocity fields per measurement section before and after 
constructing the embankment. In the analysis images obtained through post-processing of the measured images, the wind velocity was relative and the speed was shown by colors. The velocity magnitude was shown by red $>$ yellow $>$ blue colors. The speed image velocity presented in the analysis of the experiment served as a relative value; the changes in the velocity field before and after constructing the embankment were presented as color changes. The sections where tunnels were placed in the embankment had greater topographical changes than the sections without tunnels, indicating that there were larger changes in the velocity field. The velocity field of the surrounding air current had been red-colored without the embankment, but became blue-colored after constructing the embankment. As for sections A, B, and C for measurement, greater topographical changes after the embankment indicated that the velocity field of the air current was sufficiently changed before and after the embankment.

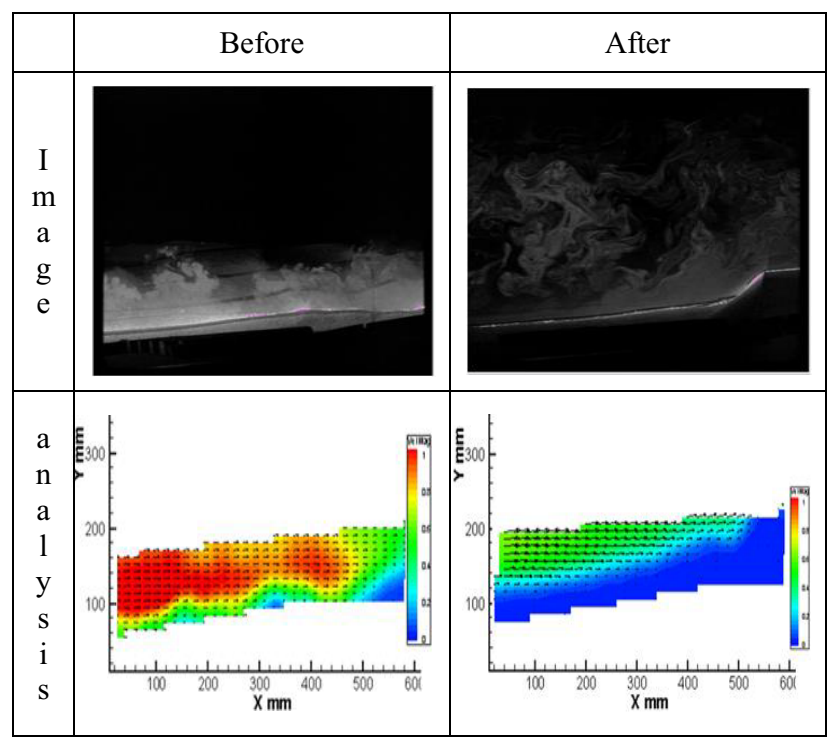

Figure 5. Images of measurement and analysis of measurement location (Center of embankment)

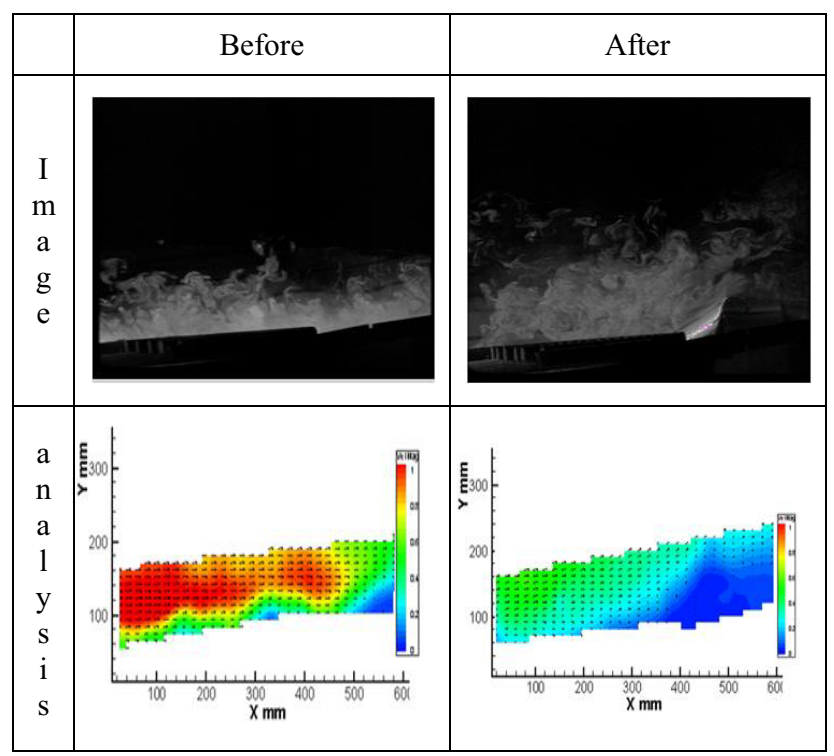

Figure 6. Images of measurement and analysis of measurement location (Section A)

\section{Conclusion}

The results of the present study on changes in wind speed around a highway embankment are as follows:

Building a highway embankment on sloping terrain affects the wind speed in the surrounding area. After building the highway embankment, the wind speed was reduced by up to $60 \%$. The reduction in wind speed was greater at points some distance away from the embankment slope relative to areas immediately below the embankment slope. The reduction in wind speed was determined in relation to the height differences of the ground below the embankment slope. Changes in wind speed around the embankment showed that the embankment slope greatly affected the reduction in wind speed.

\section{Acknowledgment}

This work is supported by the National Research Foundation of Korea (NRF) grant funded by the Korea government. (MEST) (NO.2011-0028567).

\section{References}

1. P.S. Jackson, J.C.R. Hunt, Turbulent flow over a low hill, QJRMS, 101, pp.929-955, (1975)

2. A.J. Bowen, The prediction of mean wind speeds above simple 2-D hill shapes, JWEIA, 15, pp.259270, (1983)

3. P.A.Tayor, R.J.Lee, Simple guidelines for estimating wind speed variations due to small scale topographic features, Climatological Bulletin (Canada), 18(2), pp.3-32, (1984)

4. G.Y.K. Chock, L. Cochran, Modeling of topographic wind speed effects in Hawaii, JWEIA, 93, pp.623638, (2005)

5. A.S. Sergio, P. Santiago, L.G. Oscar, S.A. Angel, Wind Tunnel Analysis of the Aerodynamic Loads on Rolling Stock over Railway Embankments: The Effect of Shelter Windbreaks, Scientific World J, 2014 , pp.1-17,(2014)

6. Y.M. Kim, K.P. You, and J.Y. You, Characteristics of wind velocity and temperature change near an escarpment-shaped road embankment, The Scientific World J, 2014, pp.1-13(2014) 